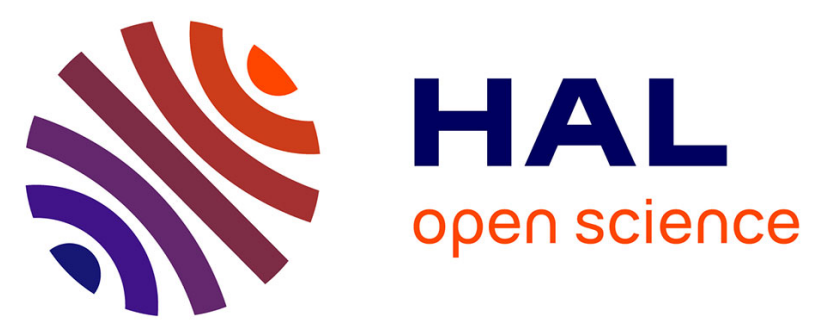

\title{
Development and validation of a screening procedure of microalgae for biodiesel production: Application to the genus of marine microalgae Nannochloropsis
}

Aumaya Taleb, Jeremy Pruvost, Jack M Legrand, Helene Marec, Benjamin B. Le Gouic, Boris Mirabella, B. Légeret, S. Bouvet, G. Peltier, Yonghua Li-Beisson, et al.

\section{To cite this version:}

Aumaya Taleb, Jeremy Pruvost, Jack M Legrand, Helene Marec, Benjamin B. Le Gouic, et al.. Development and validation of a screening procedure of microalgae for biodiesel production: Application to the genus of marine microalgae Nannochloropsis. Bioresource Technology, 2015, 177, pp.224-232. 10.1016/j.biortech.2014.11.068 . hal-02548606

\section{HAL Id: hal-02548606 https://hal.science/hal-02548606}

Submitted on 20 Apr 2020

HAL is a multi-disciplinary open access archive for the deposit and dissemination of scientific research documents, whether they are published or not. The documents may come from teaching and research institutions in France or abroad, or from public or private research centers.
L'archive ouverte pluridisciplinaire HAL, est destinée au dépôt et à la diffusion de documents scientifiques de niveau recherche, publiés ou non, émanant des établissements d'enseignement et de recherche français ou étrangers, des laboratoires publics ou privés. 


\title{
Development and validation of a screening procedure of microalgae for biodiesel production: Application to the genus of marine microalgae Nannochloropsis
}

\author{
A. Taleb ${ }^{\mathrm{a}, \mathrm{e}, \mathrm{f}}$, J. Pruvost ${ }^{\mathrm{a}, *}$, J. Legrand ${ }^{\mathrm{a}}$, H. Marec ${ }^{\mathrm{a}}$, B. Le-Gouic ${ }^{\mathrm{a}}$, B. Mirabella ${ }^{\mathrm{b}, \mathrm{c}, \mathrm{d}}$, B. Legeret ${ }^{\mathrm{b}, \mathrm{c}, \mathrm{d}}$, S. Bouvet ${ }^{\mathrm{b}, \mathrm{c}, \mathrm{d}}$, \\ G. Peltier ${ }^{\mathrm{b}, \mathrm{c}, \mathrm{d}}$, Y. Li-Beisson ${ }^{\mathrm{b}, \mathrm{c}, \mathrm{d}}$, S. Taha ${ }^{\mathrm{e}}, \mathrm{H}$. Takache ${ }^{\mathrm{f}}$ \\ ${ }^{a}$ GEPEA, Université de Nantes, CNRS, UMR6144, bd de l'Université, CRTT, BP 406, 44602 Saint-Nazaire Cedex, France \\ ${ }^{\mathrm{b}}$ CEA, IBEB, Lab Bioenerget Biotechnol Bacteries \& Microalgues, Saint-Paul-lez-Durance, F-13108, France \\ ${ }^{c}$ CNRS, UMR 7265 Biol Veget \& Microbiol Environ, Saint-Paul-lez-Durance, F-13108, France \\ ${ }^{\mathrm{d}}$ Aix Marseille Université, BVME UMR7265, Marseille, F-13284, France \\ e Department of Food Science and Technology, Faculty of Agricultural and Veterinary Medicine, Lebanese University, Dekwaneh, Beirut, Lebanon \\ ${ }_{\mathrm{f}}^{\mathrm{f}}$ AZM Center for Biotechnology Research and its Applications, Laboratory of Applied Biotechnology, Lebanese University, EDST, Tripoli, Lebanon
}

\section{H I G H L I G H T S}

- Nannochloropsis strains were screened under nitrogen replete and deplete conditions.

- Screening criteria included biomass and TAG productivities and TAG quality.

- Lipidomic profiling provides a complete view of each specie's lipidome.

- There was up to 5-fold difference in TAG productivity among the 9 strains screened.

- CCMP527 and CCMP537 were the most promising seawater strains for biodiesel production.

\section{A R T I C L E I N F O}

\section{Article history:}

Received 13 September 2014

Received in revised form 14 November 2014

Accepted 15 November 2014

Available online 20 November 2014

\section{Keywords:}

Photobioreactors

Triglycerides

Lipids

Microalgae

Biodiesel

\begin{abstract}
A B S T R A C T
Nannochloropsis has emerged as a promising alga for biodiesel production. However, the genus consists of 6 species and hundreds of strains making strain selection a challenge. Furthermore, oil productivity is instrumental to economic viability of any algal strain for industrial production, which is dependent on growth rate and oil content. In most cases, these two parameters have been studied independently. Thus, the goal of this study is to provide a combined method for evaluating strain performance in specially designed photobioreactors together with an in-depth lipidomic analyses. The nine strains of Nannochloropsis tested showed considerable variations in productivity and lipidomics highlighting the importance of strain selection. Finally, Nannochloropsis gaditana CCMP527 and Nannochloropsis salina CCMP537 emerged as the two most promising strains, with an oil content of 37 and 27 dry wt\% after 11-day nitrogen starvation, respectively, resulting in TAG productivity of $13 \times 10^{-3}$ and $18 \times 10^{-3} \mathrm{~kg} \mathrm{~m}^{-3} \mathrm{~d}^{-1}$, respectively.
\end{abstract}

\section{Introduction}

Recent concerns over availability of oil reserves have raised several fears over the long term supply of petroleum. According to many analysts, at the present rates of consumption, the world fossil oil reserves will be exhausted in less than 50 years (Rodolfi et al., 2009). In addition, fossil fuel combustion is a major source of greenhouse gases responsible for global warming. Society's dependence on fossil fuels, mainly in the transport sector, has led

\footnotetext{
* Corresponding author. Tel.: +33 (0)2 401726 68; fax: +33 (0)2 40172618 .

E-mail address: jeremy.pruvost@univ-nantes.fr (J. Pruvost).
}

to significant advances in the field of renewable energy research and more specifically, on the production of renewable liquid fuels. Among the various potential solutions, microalgae have emerged as a promising feedstock for biodiesel production (Elsey et al., 2007; Li et al., 2008). The development of a microalgae-based technology for biodiesel production has the potential to improve our common environment and move the world beyond a petroleum-based economy.

Microalgae present larger biomass growth rates and productivity when compared to conventional forestry, agricultural crops, and other aquatic plants. Furthermore, lipid synthesis, especially non-polar lipids in the form of triglycerides (TAGs), a suitable 


\section{Nomenclature}

$\begin{array}{ll}\text { PBR } & \text { photobioreactor } \\ a_{\text {light }} & \text { specific illuminated area for the photobioreactor }\left[\mathrm{m}^{-1}\right] \\ C_{X} & \text { biomass concentration }\left[\mathrm{kg} \mathrm{m}^{-3}\right] \\ D & \text { dilution rate }\left[\mathrm{h}^{-1}\right] \\ q & \text { total radiation received on photobioreactor surface } \\ & \text { (same as photon flux density) }\left[\mu \mathrm{mol} \mathrm{s} \mathrm{m}^{-2}\right] \\ P_{V} & \text { volumetric biomass productivity }\left[\mathrm{kg} \mathrm{m}^{-3} \mathrm{~d}^{-1}\right] \\ r_{X} & \text { rate of biomass production }\left[\mathrm{kg} \mathrm{m}^{-3} \mathrm{~d}^{-1}\right]\end{array}$

$S_{L}$

$t$

$N$

$V_{r}$

$\tau_{P}$

FA

TAGs

\author{
illuminated area of the photobioreactor $\left[\mathrm{m}^{2}\right]$ \\ time [days] \\ number of cells per milliliter of culture [Cells ml ${ }^{-1}$ ] \\ photobioreactor volume $[\mathrm{ml}]$ \\ hydraulic residence time [h] \\ fatty acids \\ triacylglycerols
}

feedstock for biodiesel production after transesterification, can be greatly increased by varying growth conditions (Van Vooren et al., 2012; Kandilian et al., 2014). The concentration of total lipids can indeed reach $\sim 30$ dry wt\% in optimum growth conditions (Chisti, 2007), but usually with a rather low TAG content. Higher cellular TAG content is mainly achieved during nutrient limitation or deprivation (Van Vooren et al., 2012). In general, this leads to lower TAG productivity, as biomass growth rate is reduced during nitrogen starvation.

The chemical profile of TAG is also an important parameter which has to be considered with regards to specific biodiesel applications as currently set by European Standard EN 5509. Oxidative stability is for example an important criterion, as it measures how long a fuel can resist oxidative degradation. The latter decreases with increasing number of double bonds in the fatty acids. For example, oils rich in linoleic (C18:2n-6) and linolenic $(\mathrm{C} 18: 3 n-3)$ acids tend to have poor oxidative stability (Stansell et al., 2012).

As a consequence, one of the significant challenges that must be overcome for profitable microalgae biodiesel production is the selection of microalgae with large lipid productivity (i.e. a combination of large growth rate and a large cellular TAG content) that feature also a TAG profile suitable for biodiesel application. This makes strain selection challenging, especially due to the dependency of photosynthetic metabolism to cultivation conditions, which globally affects biomass growth rate, TAG accumulation, and TAG profile. Therefore, it is necessary to sufficiently control cultivation conditions during the screening procedure.

Among the most interesting microalgae for biodiesel production is the genus Nannochloropsis. It can accumulate large amounts of lipids in the form of TAGs and can easily be cultivated at industrial scales (Rodolfi et al., 2009; Boussiba et al., 1987). It has recently emerged as one of the best candidates for the production of microalgal biodiesel (Rodolfi et al., 2009; Renaud et al., 1991; Scragg et al., 2002). Nannochloropsis is however currently comprised of 6 species (Table 1), five of which are widely distributed

Table 1

Names, species and culture collection origin of the nine strains tested in this study.

\begin{tabular}{llll}
\hline Strain full name & Abbreviation & $\begin{array}{l}\text { Culture } \\
\text { collection }\end{array}$ & Environment \\
\hline Nannochloropsis oculata 525 & CCMP525 & NCMA/CCMP & Seawater \\
Nannochloropsis oculata & AB & Alphabiotech & Seawater \\
Nannochloropsis salina 537 & CCMP537 & NCMA/CCMP & Seawater \\
Nannochloropsis salina 538 & CCMP538 & NCMA/CCMP & Seawater \\
Nannochloropsis granulata 529 & CCMP529 & NCMA/CCMP & Seawater \\
Nannochloropsis gaditana 527 & CCMP527 & NCMA/CCMP & Seawater \\
Nannochloropsis limnetica 505 & CCMP505 & NCMA/CCMP & Freshwater \\
Nannochloropsis sp. 531 & CCMP531 & NCMA/CCMP & Seawater \\
Nannochloropsis sp. 1779 & CCMP1779 & NCMA/CCMP & Seawater
\end{tabular}

Note: except one strain of Nannochloropsis oculata (obtained from the Alpha Biotech, an algae company based in France), all the other strains used in this study were purchased from the National Center for Marine Algae and Microbiota (NCMA), previously it was called 'Culture Collection of Marine Phytoplantton' (CCMP). in the marine ecosystems especially in coastal waters. These are Nannochloropsis oculata, Nannochloropsis salina, Nannochloropsis granulata, Nannochloropsis oceanica, and Nannochloropsis gaditana (Andersen et al., 1998; Fawley and Fawley, 2007). On the other hand, Nannochloropsis limnetica is the only species found in freshwater. In addition, each species include several isolates or strains (dozens to thousands), illustrating the enormous task required to screen all these microalgae for a given industrial application, especially when those applications have specific requirements as it is the case for biodiesel production.

High-throughput screening approaches are currently available and they can give valuable data for that purpose (Siaut et al., 2011). The usual approach is to test a large number of strains in parallel by combining for example 96-well plates and flow cytometer. For example, biomass productivity can be obtained under different conditions by cell counting, and lipid content can be evaluated based on Nile red fluorescence method. However, this requires a special attention because of the high dependence of lipids (and TAGs) to cultivation conditions, like nutrient availability, which drastically affects lipid metabolism. As a consequence, a second step is usually required to validate the obtained results in better-controlled conditions and in a more quantitative manner.

Several studies aiming at identifying promising oleaginous microalgal strains have already been reported in literature (Rodolfi et al., 2009; Breuer et al., 2012; Gouveia and Oliveira, 2009; Hempel et al., 2012). Due to different experimental conditions, a large variation in lipid or TAG productivity was reported, making it difficult to compare data reported in those studies. In most of these previous studies, the screening of the strains were performed in batch mode and in flasks (Sydney et al., 2011; Breuer et al., 2012; Nascimento et al., 2013; Rodolfi et al., 2009). This permitted a fast screening of a large set of microalgae species. However, this procedure did not allow for monitoring and rigorous control of the culture conditions such as $\mathrm{pH}$ and temperature, which greatly affect growth and cell metabolism of microalgae (Breuer et al., 2013; Converti et al., 2009; Wang et al., 2012). Moreover, due to the short time-scale of the experiments, typically 7-10 days, the strains were not allowed to fully adapt to culture conditions. This could introduce further bias in the results obtained. To allow for a better control of culture conditions and long-term experiments, some studies were conducted in large volume photobioreactors (Rodolfi et al., 2009; Hempel et al., 2012; Griffiths et al., 2012). However, the use of these systems for strain screening required more space and time, and was more costly. As a result, this limited the number of strains screened.

Whatever the screening approach, most of these studies focused on the ability of the strains to accumulate lipids. For example, maximum lipid content of a strain after nitrogen starvation was considered as the screening criterion. Kinetics of TAG accumulation was rarely monitored which is an important consideration in estimating the TAG productivity of the strain. In addition, only few of those studies reported TAG content and profiles despite the fact that the latter affects the quality of the produced oil or biodiesel 
(Knothe, 2005, 2009). Majority of the works showed total lipid productivity of the strains and the total fatty acids profiles, since traditional TAG quantification and profiling requires the timeconsuming separation of TAG fraction from total lipids extract. To the best of our knowledge, no study has reported a complete characterization of various strains in similar and well-controlled conditions, with an identification that supports all the relevant screening criteria for biodiesel production (e.g. facility of culture, TAG productivity, TAG profiles, etc...).

This work aims at developing a screening procedure taking into account relevant criteria of the biodiesel application, such as cellular TAG content, composition and productivity, but also the strain's ability to be cultivated in photobioreactors (PBR). Particular attention was paid to the control and reliability of culture conditions, to propose a reproducible method allowing retrieving the relevant criteria of the final application. This led to the development of a small-scale automated and fully-controlled PBR that could screen up to 6 strains of microalgae in identical conditions in batch, semi-continuous, or continuous modes.

Simultaneously, we have also applied the Liquid ChromatographyMass spectrometry/Mass spectrometry (LC-MS/MS) to probe TAG composition present in the lipidome of strains at a given culture conditions. This approach proved to be efficient and time-saving in evaluating the quality of the neutral lipids in a particular alga for a given condition.

\section{Methods}

\subsection{Strains and cultivation in shake flasks}

Nine Nannochloropsis strains were investigated, seven of which belonged to five different species of Nannochloropsis (oculata, salina, granulata, gaditana and limnetica); while species of the two other strains (Nannochloropsis sp. CCMP531 and CCMP1779) were unknown. With the exception of $N$. oculata (abbreviated as $A B$ here), all the other Nannochloropsis strains were procured from the National Center for Marine Algae and Microbiota (Bigelow Laboratory for Ocean Sciences, Maine U.S.A.). The strains along with their names, their species and their origin are listed in Table 1. They were grown in artificial seawater (Berges et al., 2001) enriched with modified Conway medium (3N3P) for nutrient replete semi-continuous cultivation, and nitrogen-free Conway medium for the sudden nitrogen starvation batch cultures. For all the experiments, salinity of seawater was adjusted to $25 \mathrm{gl}^{-1}$, and the $\mathrm{pH}$ of the medium was adjusted to 8 .

For routine small scale laboratory analyses, cultures of Nannochloropsis species were cultivated at $25^{\circ} \mathrm{C}$ in an Incubator set at $110 \mathrm{rpm}$ with constant illumination of $100 \mu$ moles photons $\mathrm{m}^{-2} \mathrm{~s}^{-1}$, and supplied with $2 \% \mathrm{CO}_{2}$. Typically, cultures were initiated with a seed culture from an agar plates, and propagated until mid-log phase, then diluted a couple of times in fresh medium to ensure homogenous culturing. To induce nitrogen stress, mid-log phase grown cells were centrifuged for $3 \mathrm{~min}$ at $6000 \mathrm{~g}$ at room temperature, and cell pellets were washed with an equal volume of Conway- $\mathrm{N}$ medium twice before finally suspending cells into the Conway- $\mathrm{N}$ medium.

\subsection{Cultivation in efficient overproducing screening system- photobioreactors (EOSS-PBR)}

A specific cultivation system adapted to the screening of microalgae in reliable conditions was developed as shown Fig. 1. This system was named EOSS-PBR, especially made with polymethyl methacrylate (PMMA). It was used for evaluating cell growth and productivity measurement. It consisted of 6 small-scale PBRs (bubble columns) operated in parallel, each tube had a volume $V_{r}=30 \mathrm{ml}$ and an illuminated area $S_{L}=0.008 \mathrm{~m}^{2}$. EOSS-PBR was fully automated in terms of medium injection and biomass harvesting to allow semi-continuous cultivation, with the ability to set different feeding or harvesting sequences in each tube. A sequence was defined by the feeding/harvesting flow rate, its time of application, and its duration. In this study, because the aim was to compare strains, identical parameters were applied for all the PBRs. The maximum deviation in the daily dilution rates during the semi-continuous cultivation in each tube was measured to be less than $10 \%$.

The $\mathrm{pH}$ and the temperature were regulated at 8 and $25^{\circ} \mathrm{C}$, respectively, by continuous injection of air with $2 \mathrm{vol} \% \mathrm{CO}_{2}$ at a flow rate of $3 \mathrm{ml} \mathrm{min}^{-1}$. The incident photons flux density (PFD) was provided by a set of 6 white fluorescent light tubes so as to obtain a constant PFD of $150 \mu$ moles $\mathrm{m}^{-2} \mathrm{~s}^{-1}$ for nutrient replete cultivation experiments, and $250 \mu$ moles $\mathrm{m}^{-2} \mathrm{~s}^{-1}$ for the sudden nitrogen starvation experiments, following the protocol set by Van Vooren et al. (2012).

\subsection{Analytical methods}

\subsubsection{Cell count}

In order to characterize strain growth kinetics, the growth curve of each strain was defined as the evolution of the number of cells as a function of time $(t)$. Cell concentration $N$ was expressed as number of cells per milliliter of culture was determined for all the strains under an optical microscope using Malassez counting cell. For small scale lipidomic experiments, cell concentration was calculated using a Coulter Multisizer ${ }^{\mathrm{TM}} 3$ Coulter Counter (Beckman).

\subsubsection{Dry weight and biomass productivity}

The algal dry weight concentration $C_{X}$ was determined by filtration through a pre-dried and pre-weighed glass-fiber filter (Whatman GF/F). The filters were dried $24 \mathrm{~h}$ at $105^{\circ} \mathrm{C}$, cooled down in a desiccator and then weighed again. Given results are the averages of three measurements. The volumetric biomass productivity $P_{V}$ in the continuous cultures was deduced from biomass concentration $C_{X}$ measured at steady-state (Pruvost et al., 2008):

$P_{V}=r_{X}=\frac{C_{X}}{\tau_{P}}$

Here $\tau_{P}$ corresponded to the microalgae residence time in the PBR as fixed by the liquid flow rate of fresh medium applied in the feed (with $\tau_{P}=\frac{1}{D}$, where $D$ is the dilution rate). Please note that in continuous mode at steady-state, volumetric biomass productivity $P_{V}$ is equal to the biomass growth rate $r_{X}$ (Pruvost and Cornet 2012; Pruvost et al., 2008).

\subsubsection{Lipid extraction and TAG quantification}

Total lipids were extracted and the cellular TAG content was quantified based on the methods previously reported in our laboratories (Van Vooren et al., 2012; Siaut et al., 2011). The rate of biomass production $r_{X}$ in batch conditions applied during nitrogen deprivation experiments was obtained by taking the time derivative of the biomass concentration evolution on the total culture duration $T=11$ days:

$r_{X}=\frac{C_{X_{t=11 d}}-C_{X_{t=0}}}{T}$

Volumetric TAG productivity was calculated as the product of biomass production rate and TAG content at the eleventh day of starvation. 


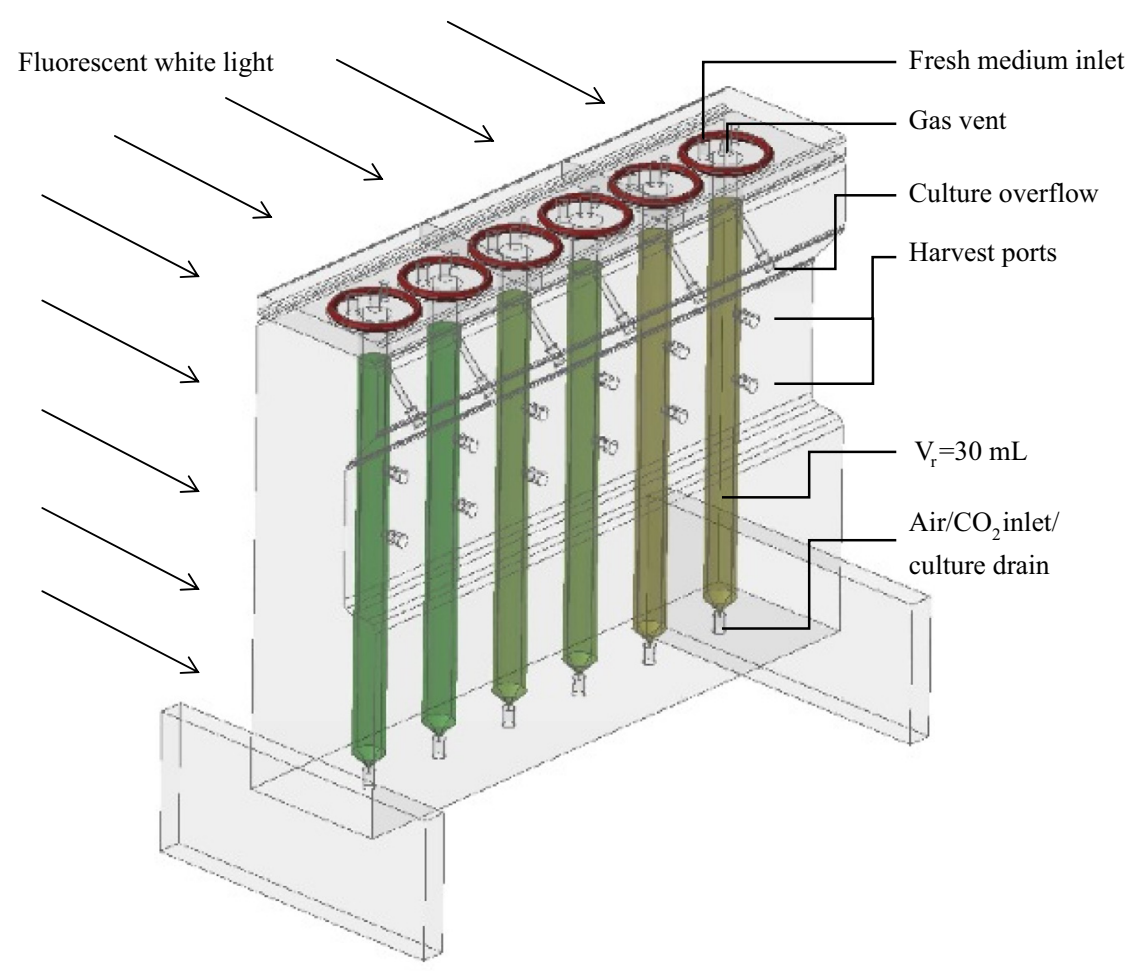

Fig. 1. Schematic representation of "EOSS-PBR".

2.3.4. Lipid molecular species analyses by ultra-performance Liquid Chromatography coupled to tandem Mass Spectrometry (LC-MS/MS)

LC-MS/MS analyses were following that of previously described in Nguyen et al. (2013), with the exception that quantification was done using the triheptadecaonoin (TAG17:0/17:0/17:0) as an internal standard for TAGs, and phosphatidylethanolamine (PE17:0/ 17:0) for polar lipid species.

\section{Results and discussion}

\subsection{Design of the general screening strategy used in this study}

In view of the many species and hundreds of strains available within the genus of Nannochloropsis, in this study, we have set up a method to screen the 'optimal' strains suitable for potential biodiesel production. Nannochloropsis strains were evaluated based on 4 criteria: (1) biomass productivity and (2) culture behavior under normal growth condition, and (3) biomass and (4) TAG productivities during sudden nitrogen starvation. In parallel, a full lipidomic analysis of the composition and distribution of lipid molecule species inherent to each strain was also carried out. This simultaneously yields important information on the quality of TAGs produced. When combined together, these analyses should allow us to identify optimal strains in terms of TAG productivity and quality within the genus of Nannochloropsis for biodiesel production.

\subsubsection{Establishing an efficient overproducing screening system- photobioreactor (EOSS-PBR)}

EOSS-PBR permits batch as well as semi-continuous cultivation. This last feature was found relevant to allow the strains issued from various collections to adapt progressively to the growth conditions of PBR cultivation. In some cases, it was indeed found necessary to wait for several weeks before reaching a stable biomass production, indicating progressive adaptation of the cultivated strain to the conditions applied. During this semi-continuous cultivation, an average residence time $\tau_{P}=100 \mathrm{~h}\left(D=0.01 \mathrm{~h}^{-1}\right)$ was imposed to prevent culture washout during the period of cell adaptation to the EOSS-PBR conditions. Biomass concentration was measured once the culture reached a steady-state. The latter was determined by monitoring cell concentration daily. Steady state was reached when the cell concentration of each culture remained constant for three consecutive days. Biomass productivity was then determined. Strains with the largest biomass productivity were then re-suspended in nitrogen-free media in a second EOSS-PBR for TAG accumulation. Culture were diluted for similar initial biomass concentration $\left(C_{X}=0.2 \mathrm{~kg} \mathrm{~m}^{-3}\right)$, and lipid and TAG concentration were measured on the eleventh day of cultivation, which correspond to the approximate duration necessary for maximal TAG accumulation (Van Vooren et al., 2012).

\subsubsection{Lipid molecular species identification and screening based on LC-MS/MS}

The utility and composition of TAGs are determined largely by its fatty acid composition regarding total acyl chain length and number of unsaturations. Traditional TAG compositional analyses are lengthy requiring lipid extractions, recovery of TAG fraction by TLC-based separation, and conversion to fatty acid methyl esters (FAMEs) then analyzed by gas chromatographic method (Siaut et al., 2011). In this study, we have adopted the use of LC-MS/MS to profile cellular lipidome in its native state, i.e. can be applied on direct lipid extract without involving chemical conversion process. LC-MS/MS analyses provide a full picture of lipidome including the relative abundance of each molecular species. It gave the relevant quantity, quality and molecular species distribution in one single analysis which takes less than $1 \mathrm{~h}$ when the positive and negative modes were combined. This allows a complete identification of the total polar lipid and TAG molecular species in the genus of Nannochloropsis. It must be noticed, this is a first complete list of the polar lipidome for the genus of Nannochloropsis, and thus will serve as a blueprint for our later comparative analyses. 


\subsection{Pre-screening in "EOSS-PBR" for growth and biomass productivity}

3.2.1. Quantitative and qualitative characterization of strains under standard growth conditions in EOSS-PBR run in semi-continuous mode

During the first evaluation, all investigated cultures in semicontinuous mode were only light-limited, i.e. there was no mineral or nutrient limitation during their growth as described in (Pruvost et al., 2009). The EOSS-PBR were exposed to constant culture conditions, with PFD of $150 \mu$ moles $\mathrm{m}^{-2} \mathrm{~s}^{-1}$ and residence time $\tau_{P}=100 \mathrm{~h}$ (i.e. dilution rate $D=0.01 \mathrm{~h}^{-1}$ ).

Fig. 2 shows the steady-state biomass concentration and volumetric biomass productivity for all the nine strains of Nannochloropsis. Although all strains were issued from the same genus, there was a large variation in productivity, even after the adaptation period which was found necessary to achieve a stable production. As shown in Fig. 3 which gives time courses of cultivation, a period of 2-4 days was found necessary to achieve steadystate, showing here a rather quick adaptation of those strains to EOSS-PBR conditions (see also next section). Productivities ranged from $0.05 \mathrm{~kg} \mathrm{~m}^{-3} \mathrm{~d}^{-1}$ for $N$. oculata $A B$ to $0.766 \mathrm{~kg} \mathrm{~m}^{-3} \mathrm{~d}^{-1}$ for $N$. sp. CCMP1779. Strains featuring biomass productivity greater than $0.5 \mathrm{~kg} \mathrm{~m}^{-3} \mathrm{~d}^{-1}$ were selected for further screening (TAG accumulation in nitrogen-free medium). The four strains that met this criterion were $N$. sp. CCMP1779, N. salina CCMP537, $N$. sp. CCMP531 and $N$. gaditana CCMP527 with productivities of $0.766 \mathrm{~kg} \mathrm{~m}^{-3} \mathrm{~d}^{-1}, \quad 0.729 \mathrm{~kg} \mathrm{~m}^{-3} \mathrm{~d}^{-1}, \quad 0.500 \mathrm{~kg} \mathrm{~m}^{-3} \mathrm{~d}^{-1}$ and $0.538 \mathrm{~kg} \mathrm{~m}^{-3} \mathrm{~d}^{-1}$, respectively.

\subsubsection{Comparison of strain growth kinetics and behavior in $P B R$ cultivation conditions}

In addition to the quantitative characterization of strains' growth such as volumetric biomass productivity, additional criteria relevant for their cultivation were considered in the selection procedure, like possible biofilm formation or cell settlement during their cultivation. Here, the cultivation of all Nannochloropsis strains in the EOSS-PBR apart from N. salina CCMP538 was found straightforward and unchallenging. As shown in Fig. 3, N. salina CCMP538 was found to have a low initial growth and cells began to die on the fourth day of cultivation, emphasizing a lack of growth robustness. By contrast, the remaining strains were much easier to cultivate as confirmed by their quick adaptation to the PBR conditions after its inoculation. Cell settlement and biofilm formation were observed for several of the strains. These strains were N. limnetica CCMP505,

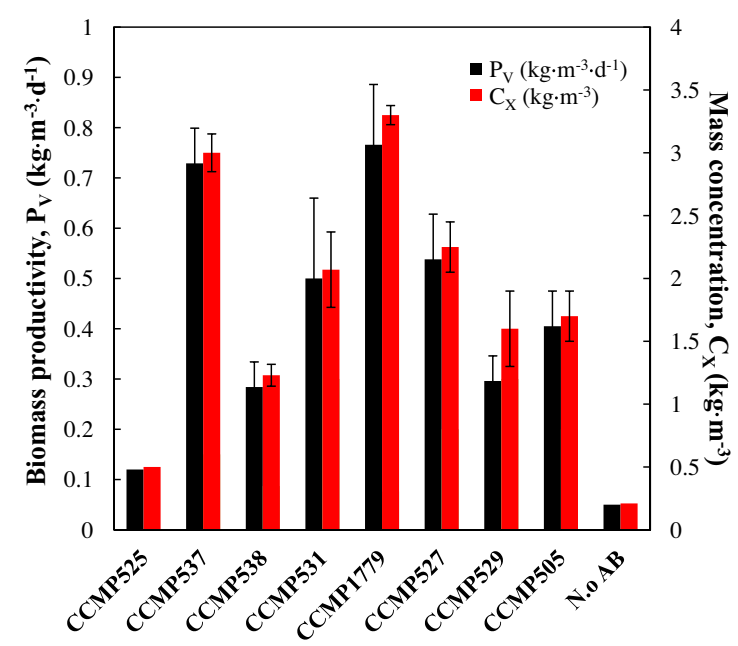

Fig. 2. Biomass concentration $\left(C_{X}\right)$ and volumetric biomass productivity $P_{V}$ for nine Nannochloropsis strains as achieved at steady-state under normal growth conditions (replete nitrogen).

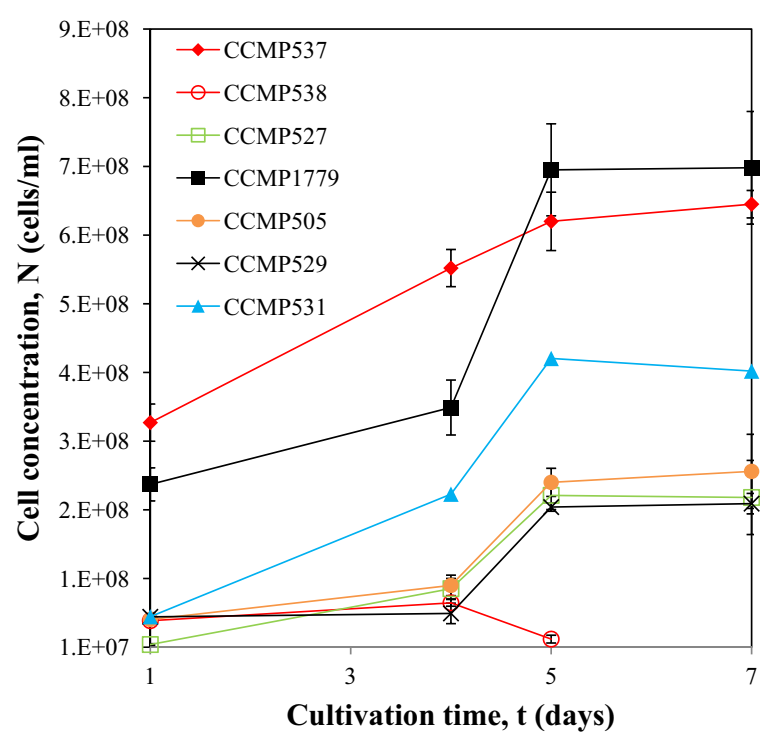

Fig. 3. Time evolution of cell concentration in semi-continuous production under normal growth conditions.
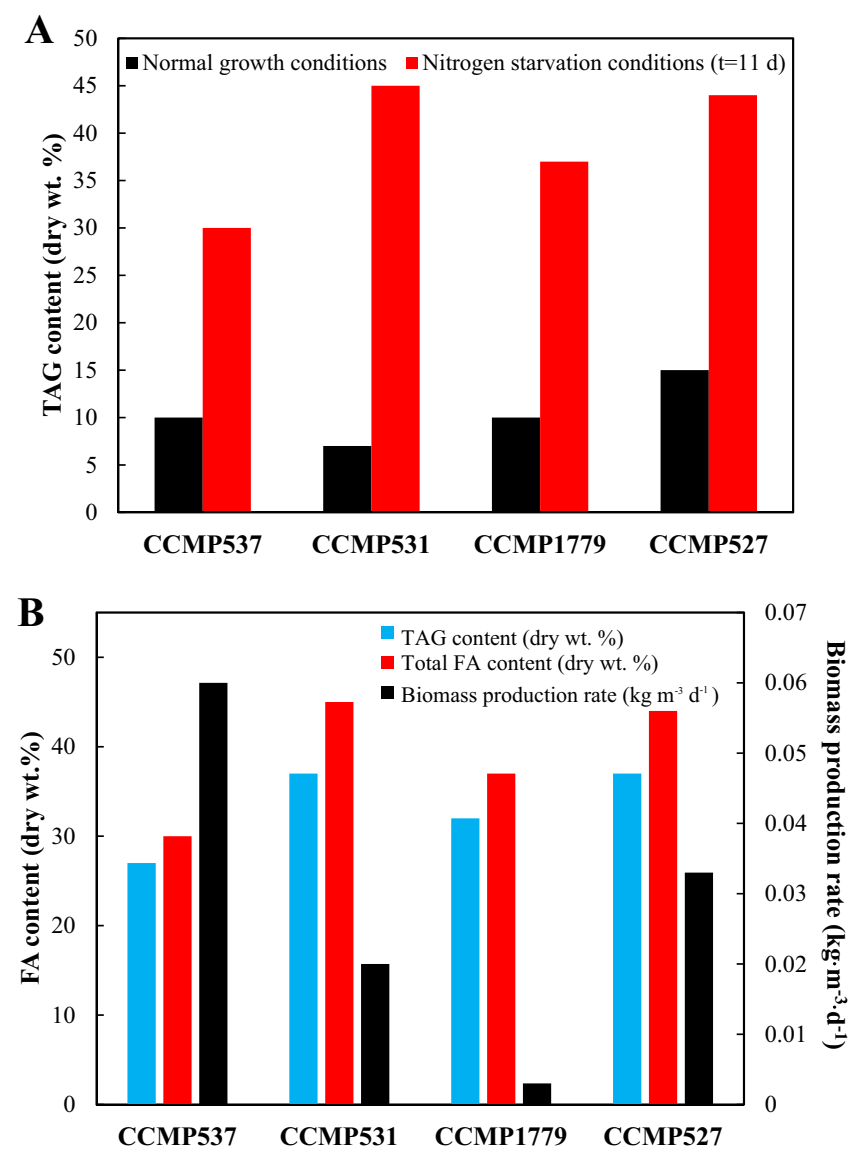

Fig. 4. (A) Fold increase in TAG content for the four selected strains under normal growth and sudden nitrogen starvation conditions in EOSS-PBR; (B) biomass production rate for the 4 strains under sudden nitrogen starvation and characterization of the total FA and TAG content at the eleventh day of starvation.

N. oculata AB, N. granulata CCMP529 and N. salina CCMP538. Fortunately, the most productive strains (i.e. N. sp. CCMP1779, N. salina CCMP537, N. sp. CCMP531 and $N$. gaditana CCMP527) were found to grow well in the PBR without hindrance. 
3.3. Investigation of total fatty acids and TAG accumulation and corresponding productivities

The four selected strains according to their volumetric biomass productivities were cultivated in batch mode for a period of eleven days in nitrogen-free medium (sudden nitrogen starvation). Fig. 4A shows that the TAG content of cells of all four strains increased drastically under nitrogen starvation conditions. The TAG concentration of $N$. gaditana CCMP527, $N$. salina CCMP537, $N$. sp. CCMP1779, and $N$. sp. CCMP531 were, respectively, three, four, six, and seven times higher than their corresponding values during optimal growth conditions. Since a two to three fold increase was observed in total fatty acids of all four species after nitrogen starvation, we suggest that TAGs accumulated under nitrogen starved Nannochloropsis partly came from de novo synthesis, and partly from remodeled membrane fatty acids as in cells of the green alga Chlamydomonas reinhardtii (Siaut et al., 2011). Under nitrogen starvation conditions, the fatty acids present in the TAG fraction consisted of around $80-90 \%$ of total cellular fatty acids, at least for the four chosen strains examined at the end of 11 day nitrogen starvation (results not shown).

Fig. $4 \mathrm{~B}$ shows the average rate of biomass production as well as the total fatty acids and TAG concentration (in dry wt\%) obtained on the eleventh day of cultivation for each strain under nitrogen starvation conditions. The strain $N$. salina CCMP537 achieved the largest biomass production rate during nitrogen deprivation, with
$r_{X}=0.060 \mathrm{~kg} \mathrm{~m}^{-3} \mathrm{~d}^{-1}$. The remaining strains, $N$. gaditana CCMP527, $N$. sp. CCMP531 and N. sp. CCMP1779 featured biomass production rates of $0.033,0.020$ and $0.004 \mathrm{~kg} \mathrm{~m}^{-3} \mathrm{~d}^{-1}$, respectively. Again, although identical conditions were applied on strains issued from the same genus, considerable difference in productivities was observed.

Common to all the strains, the biomass production rate during nitrogen starvation was found around one order of magnitude lower than the one achieved in growth-favoring conditions during continuous production (i.e. equal to biomass productivity at steady-state). This was expected as dry biomass is composed of $10-15 \%$ nitrogen and depriving the culture of nitrogen causes a significant decrease in biomass growth (Van Vooren et al., 2012). Moreover, the strains N. sp. CCMP531 and N. gaditana CCMP527 featured a total fatty acid concentration of 45 and 44 dry wt\%, respectively. These two strains also had the largest TAG content of all four strains tested with a TAG concentration of approximately 37 dry wt\%.

One of the key criteria for strain selection for biodiesel application is TAG productivity. Therefore, the best strain is ideally the one with the highest TAG concentration and at the meantime the highest biomass production rate. Batch averaged TAG productivity for the strains $N$. salina CCMP537, $N$. gaditana CCMP527, N. sp. CCMP531 and $N$. sp. CCMP1779 were found equal to 0.018, 0.013, 0.009 , and $0.004 \mathrm{~kg} \mathrm{~m}^{-3} \mathrm{~d}^{-1}$, respectively. Here, $N$. salina CCMP537 achieved the largest TAG productivity (i.e. $0.018 \mathrm{~kg} \mathrm{~m}^{-3} \mathrm{~d}^{-1}$ ) but
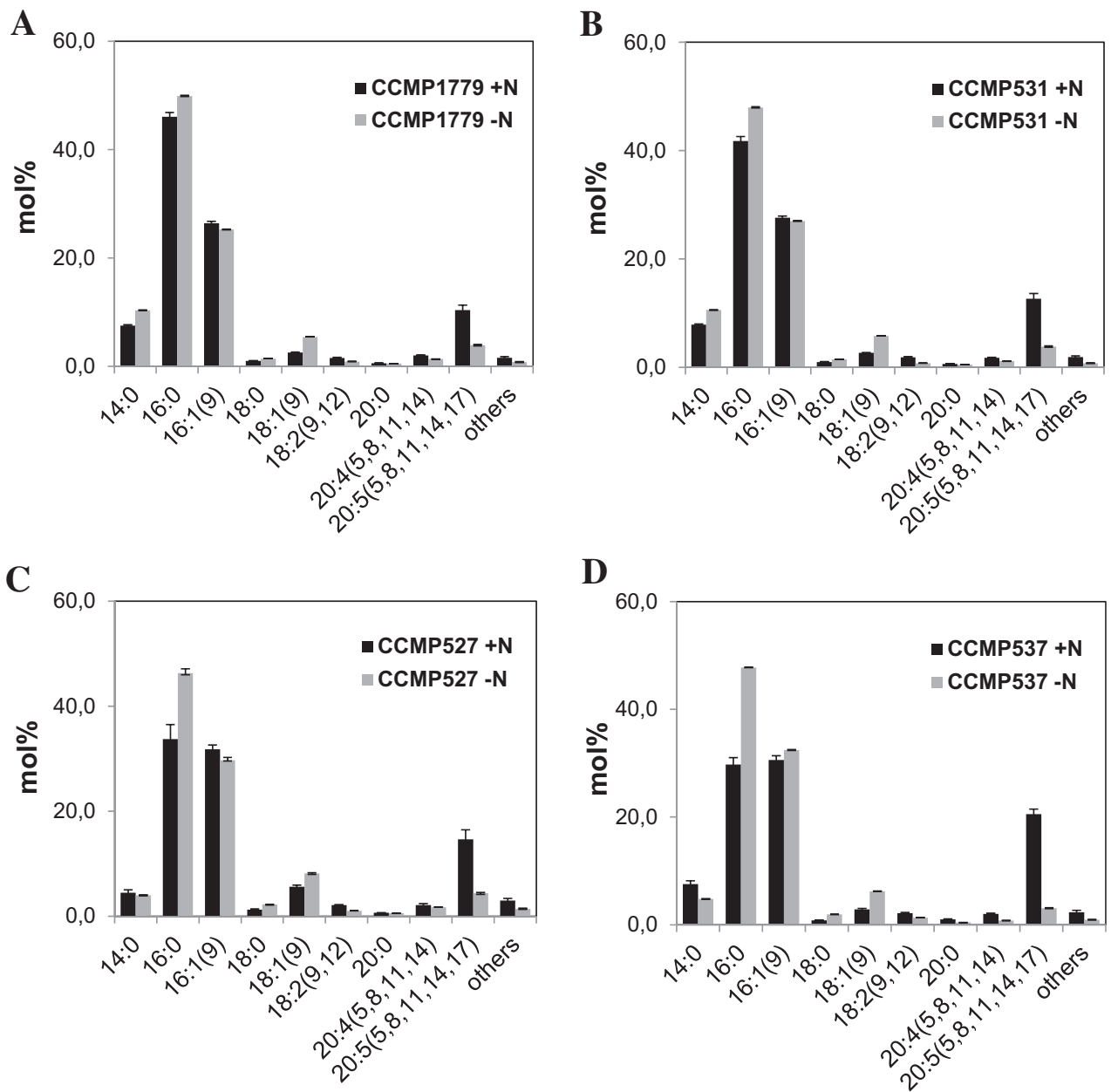

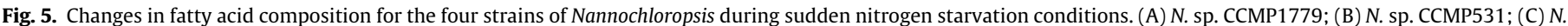

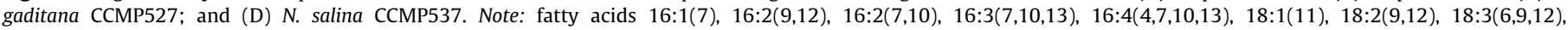
$18: 3(9,12,15), 18: 4(6,9,12,15)$ were detected by the GC-FID but grouped together as they were found less than 0.5 mol\% abundance in each strain (here named "others"). 
featured the lowest cell TAG concentration of all four strains. This was due to its large biomass growth rate during nitrogen starvation. It must be noted that this strain was found to have the second largest biomass productivity in continuous mode (nitrogen replete conditions), with $P_{V}=0.729 \mathrm{~kg} \mathrm{~m}^{-3} \mathrm{~d}^{-1}$. Another interesting candidate is here emphasized, namely $N$. gaditana CCMP527. This strain achieved the second largest TAG productivity (i.e. $0.013 \mathrm{~kg} \mathrm{~m}^{-3}$ $\mathrm{d}^{-1}$ ) but with the largest TAG concentration of 37 dry wt\%.

It is also worth mentioning that, due to the small working volume of the EOSS-PBR ( $30 \mathrm{ml}$ per tube), it was not possible to do more frequent sampling thus growth and lipid accumulation kinetics were not investigated in detail. For example, following our procedure, strains that accumulated TAG most rapidly could not be identified here. In other words, it is possible that significant TAG accumulation occurred before the final sampling after 11 days. A further screening of the strains of interest as identified in this study in PBR of higher volume should give those information, as described in (Van Vooren et al., 2012), by providing a more detailed study of the dynamics of biomass and lipids accumulation during nitrogen starvation.

\subsection{Investigation of fatty acid profiles and their suitability for biodiesel applications}

\subsubsection{Total fatty acid profiling under normal and stress conditions}

Under optimal growth conditions, strains of Nannochloropsis genus were mainly composed of 9 major fatty acids with varying carbon numbers (from C14 to C20) and varying level of unsaturation. These fatty acids included myristic acid (14:0), palmitic acid (16:0), stearic acid (18:0), oleic acid (18:1), linoleic acid (18:2), eicosanoic acid (20:0), arachidonic acid (20:4) and eicosapentaenoic acid (EPA: 20:5). Considerable variations in the fatty acid compositions were observed between different species, and also between two strains of the same species for example the $N$. salina. The two most notable variations were with the palmitic acid (16:0) and eicosapentaenoic acid (EPA: 20:5). It ranged from 25 to

A

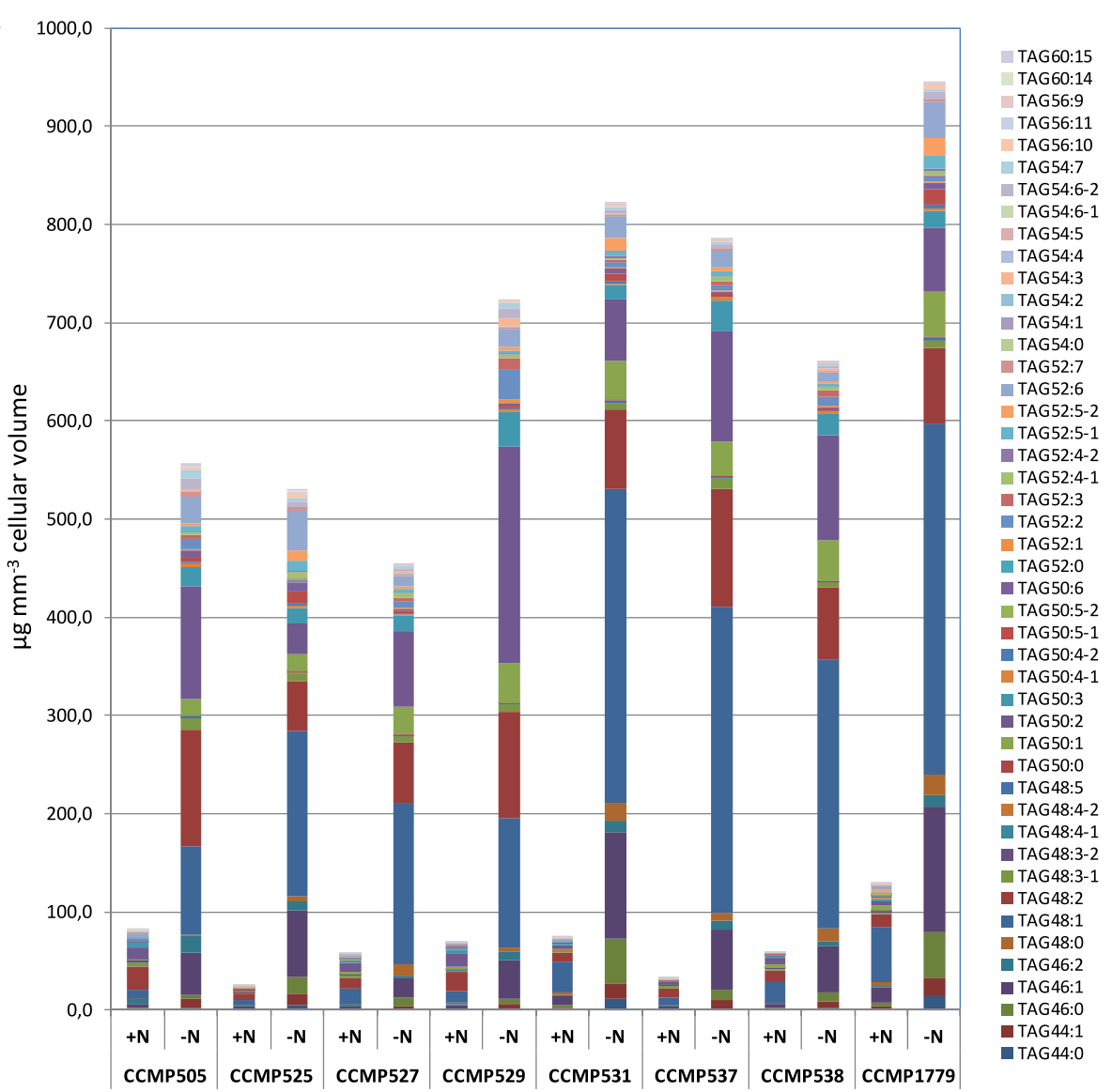

B

\begin{tabular}{|l|ccccccccc|}
\hline $\begin{array}{l}\text { TAG }(\leq 2 \text { double } \\
\text { bonds)/TAG }(\geq 3 \\
\text { double bonds) }\end{array}$ & CCMP505 & CCMP525 & CCMP527 & CCMP529 & CCMP531 & CCMP537 & CCMP538 & CCMP1779 \\
\hline +N condition & 2.4 & 2.1 & 3.9 & 4.1 & 6.4 & 3.4 & 6.2 & 5.2 \\
-N condition & 3.4 & 2.7 & 6.0 & 5.0 & 7.3 & 6.9 & 8.6 & 5.2 \\
\hline
\end{tabular}

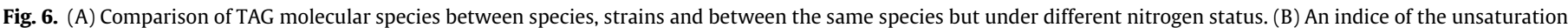

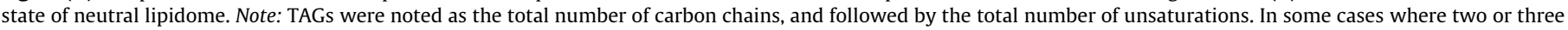
different peaks were identified with the same molecular mass, thus were noted ' -1 , or -2' etc. 
46 mol\% for palmitic acids, and from 10 to 24 mol\% for EPA, respectively. The difference in total fatty acid composition between species of the same genus illustrated significant difference in the metabolism of lipids within the genus of Nannochloropsis as it has been suggested also from comparative genome sequencing (Wang et al., 2014). All strains responded to nitrogen starvation by decreasing the relative composition of fatty acids with more than 2 double bonds including EPA, and with simultaneous increase in the composition of unsaturated and monounsaturated fatty acids (i.e. palmitic and oleic acids) (Fig. 5).

3.4.2. Monitoring changes in TAG molecular species by a lipidomic approach using LC-MS/MS and suitability for biodiesel application

To gain a comprehensive view of the difference in lipidome and in lipidomic response to nitrogen starvation between species of the same genus, we analyzed both neutral and polar lipidome for all 8 species of Nannochloropsis. Analyses of polar lipidome revealed significant reduction in most polar lipid class at the onset of nitrogen starvation, thus supporting our view that neutral lipids and especially TAGs accumulated under nitrogen starvation are partly coming from remodeled membrane lipids.

For biodiesel application, neutral lipids and especially TAGs are the most interesting feedstock. Moreover, their fatty acid profile are a critical criterion, as they affect directly properties of biodiesel (Knothe, 2005, 2009; Stansell et al., 2012). In fact, the two most important factors affecting the fuel properties are the length of the carbon chain and the number of double bonds present in the molecule. For example, according to the European biodiesel standard EN 14214, linolenic acid (C18:3n-3) and polyunsaturated fatty acids ( $\geqslant 4$ double bonds) contents must be limited to a maximum of $12 \%$ and $1 \%(\% \mathrm{~m} / \mathrm{m})$, respectively.

In this study, results showed that significant variations in TAGs content and composition were also observed here between different strains, species and also with changing nitrogen status of the cultivation medium (Fig. 6A). An estimation of the oil quality was made as a comparison of the ratio between saturated/monounsaturated fatty acids to that of fatty acids containing more than two double bonds in a given lipidome (Fig. 6B). Results showed that the strains witch presented the most important ratio $(\geqslant 6)$ under nitrogen starvation conditions were $N$. salina CCMP538 (8.6), $N$. sp. CCMP531 (7.3), N. salina CCMP537 (6.9) and $N$. gaditana CCMP527 (6). In fact, for these strains, the interesting ratio found here, were promoting to produce biodiesel of high quality, as such important ratio favors the production of biodiesel with high oxidation stability, high cetane number, and low melting point resulting in good cold flow properties and viscosity of the fuel (Stansell et al., 2012). It must also be noticed that, LC-MS/MS analyses confirmed here our findings that in response to nitrogen starvation, significant accumulation of TAGs were observed. This analysis supported our view that LC-MS/MS is an efficient way to quantify oil content and composition.

\section{Conclusions}

Nine Nannochloropsis strains were screened with regards to their potential for biodiesel production. Although those strains were issued from the same genus, important differences were observed in all criteria investigated. The two most promising strains identified here were $N$. salina CCMP537 and $N$. gaditana CCMP527. They were found easy to grow and they accumulated a large content of TAG while maintaining good biomass productivity under nitrogen starvation conditions. Volumetric TAG productivity of 0.018 and $0.013 \mathrm{~kg} \mathrm{~m}^{-3} \mathrm{~d}^{-1}$ were obtained for $N$. salina CCMP537 and $N$. gaditana CCMP527, respectively. They also possessed suitable TAG profiles for biodiesel applications. In future works, these two strains will be further investigated in larger PBR for an in-depth characterization. The method developed here will also be extended to other species, including freshwater ones.

Additional data obtained from lipidomic analysis using the Liquid Chromatography Mass spectrometry/Mass spectrometry (LC-MS/MS) are presented in Supplementary material.

\section{Acknowledgements}

This research was supported by the French National Research Agency project DIESALG (ANR-12-BIME-0001-02), the CAER project and by the Division of Life Sciences - a CEA internal funding NannoControl. Aumaya TALEB is grateful to the AUF (Francophone University Association) and the Lebanese National Council for Scientific Research (CNRS). Technical support was provided by the HélioBiotec platform, funded by the European Union (FEDER), the Région Provence Alpes Côte d'Azur, the French Ministry of Research, and the CEA.

\section{Appendix A. Supplementary data}

Supplementary data associated with this article can be found, in the online version, at http://dx.doi.org/10.1016/j.biortech.2014. 11.068 .

\section{References}

Andersen, R.A., Brett, R.W., Potter, D., Sexton, J.P., 1998. Phylogeny of the Eustigmatophyceae Based upon 18S rDNA, with Emphasis on Nannochloropsis. Protist 149, 61-74.

Berges, J.A., Franklin, D.J., Harrison, P.J., 2001. Evolution of an artificial seawater medium: improvements in enriched seawater, artificial water over the last two decades. J. Phycol. 37, 1138-1145.

Boussiba, S., Vonshak, A., Cohen, Z., Avissar, Y., Richmond, A., 1987. Lipid and biomass production by the halotolerant microalga Nannochloropsis salina. Biomass 12, 37-47.

Breuer, G., Lamers, P.P., Martens, D.E., Draaisma, R.B., Wijffels, R.H., 2012. The impact of nitrogen starvation on the dynamics of triacylglycerol accumulation in nine microalgae strains. Bioresour. Technol. 124, 217-226.

Breuer, G., Lamers, P.P., Martens, D.E., Draaisma, R.B., Wijffels, R.H., 2013. Effect of light intensity, $\mathrm{pH}$, and temperature on triacylglycerol (TAG) accumulation induced by nitrogen starvation in Scenedesmus obliquus. Bioresour. Technol. $143,1-9$.

Chisti, Y., 2007. Biodiesel from microalgae. Biotechnol. Adv. 25, 294-306.

Converti, A., Casazza, A.A., Ortiz, E.Y., Perego, P., Del Borghi, M., 2009. Effect of temperature and nitrogen concentration on the growth and lipid content of Nannochloropsis oculata and Chlorella vulgaris for biodiesel production. Chem. Eng. Process 48, 1146-1151.

Elsey, D., Jameson, D., Raleigh, B., Cooney, M.J., 2007. Fluorescent measurement of microalgal neutral lipids. J. Microbiol. Methods 68, 639-642.

Fawley, K.P., Fawley, M.W., 2007. Observations on the diversity and ecology of freshwater Nannochloropsis (Eustigmatophyceae), with descriptions of new taxa. Protist 158, 325-336.

Gouveia, L., Oliveira, A.C., 2009. Microalgae as a raw material for biofuels production. J. Ind. Microbiol. Biotechnol. 36, 269-274.

Griffiths, M.J., van Hille, R.P., Harrison, S.T.L., 2012. Lipid productivity, settling potential and fatty acid profile of 11 microalgal species grown under nitrogen replete and limited conditions. J. Appl. Phycol. 24, 989-1001.

Hempel, N., Petrick, I., Behrendt, F., 2012. Biomass productivity and productivity of fatty acids and amino acids of microalgae strains as key characteristics of suitability for biodiesel production. J. Appl. Phycol. 24, 1407-1418.

Kandilian, R., Pruvost, J., Legrand, J., Pilon, L., 2014. Influence of light absorption rate by Nannochloropsis oculata on triglyceride production during nitrogen starvation. Bioresour. Technol. 163, 308-319.

Knothe, G., 2005. Dependence of biodiesel fuel properties on the structure of fatty acid alkyl esters. Fuel Process. Technol. 86, 1059-1070.

Knothe, G., 2009. Improving biodiesel fuel properties by modifying fatty ester composition. Energy Environ. Sci. 2, 759-766.

Li, Y., Horsman, M., Wu, N., Lan, C.Q., Dubois-Calero, N., 2008. Biofuels from Microalgae. Biotechnol. Prog. 24, 815-820.

Nascimento, I.A., Marques, S.S.I., Cabanelas, I.T.D., Pereira, S.A., Druzian, J.I., de Souza, C.O., Vich, D.V., de Carvalho, G.C., Nascimento, M.A., 2013. Screening microalgae strains for biodiesel production: lipid productivity and estimation of fuel quality based on fatty acids profiles as selective criteria. BioEnergy Res. 6, $1-13$. 
Nguyen, H.M., Cuiné, S., Beyly-Adriano, A., Légeret, B., Billon, E., Auroy, P., Beisson, F., Peltier, G., Li-Beisson, Y., 2013. The green microalga Chlamydomonas reinhardtii has a single $\omega-3$ fatty acid desaturase that localizes to the chloroplast and impacts both plastidic and extraplastidic membrane lipids. Plant Physiol. 163, 914-928.

Pruvost, J., Cornet, J., 2012. Knowledge models for the engineering and optimization of photobioreactors. In: Posten, C., Walter, C. (Eds.), Microalgal Biotechnology: Potential and Production. De Gruyter, Berlin, Germany, pp. 181-224.

Pruvost, J., Cornet, J.-F., Legrand, J., 2008. Hydrodynamics influence on light conversion in photobioreactors: an energetically consistent analysis. Chem. Eng. Sci. 63, 3679-3694.

Pruvost, J., Van Vooren, G., Cogne, G., Legrand, J., 2009. Investigation of biomass and lipids production with Neochloris oleoabundans in photobioreactor. Bioresour. Technol. 100, 5988-5995.

Renaud, S.M., Parry, D.L., Thinh, L.-V., Kuo, C., Padovan, A., Sammy, N., 1991. Effect of light intensity on the proximate biochemical and fatty acid composition of Isochrysis sp. and Nannochloropsis oculata for use in tropical aquaculture. J. Appl. Phycol. 3, 43-53.

Rodolfi, L., Chini Zittelli, G., Bassi, N., Padovani, G., Biondi, N., Bonini, G., Tredici, M.R., 2009. Microalgae for oil: strain selection, induction of lipid synthesis and outdoor mass cultivation in a low-cost photobioreactor. Biotechnol. Bioeng. 102, 100-112.

Scragg, A.H., Illman, A.M., Carden, A., Shales, S.W., 2002. Growth of microalgae with increased calorific values in a tubular bioreactor. Biomass Bioenergy 23, 67-73.
Siaut, M., Cuiné, S., Cagnon, C., Fessler, B., Nguyen, M., Carrier, P., Beyly, A., Beisson, F., Triantaphylidès, C., Li-Beisson, Y., Peltier, G., 2011. Oil accumulation in the model green alga Chlamydomonas reinhardtii: characterization, variability between common laboratory strains and relationship with starch reserves. BMC Biotechnol. 11, 7.

Stansell, G.R., Gray, V.M., Sym, S.D., 2012. Microalgal fatty acid composition: implications for biodiesel quality. J. Appl. Phycol. 24, 791-801.

Sydney, E.B., da Silva, T.E., Tokarski, A., Novak, A.C., de Carvalho, J.C., Woiciecohwski, A.L., Larroche, C., Soccol, C.R., 2011. Screening of microalgae with potential for biodiesel production and nutrient removal from treated domestic sewage. Appl. Energy 88, 3291-3294, Special issue of energy from algae: current status and future trends.

Van Vooren, G., Le Grand, F., Legrand, J., Cuiné, S., Peltier, G., Pruvost, J., 2012. Investigation of fatty acids accumulation in Nannochloropsis oculata for biodiesel application. Bioresour. Technol. 124, 421-432.

Wang, B., Lan, C.Q., Horsman, M., 2012. Closed photobioreactors for production of microalgal biomasses. Biotechnol. Adv. 30, 904-912, Biorefining: Thermochemical and Enzymatic Biomass Conversion International Conference on Biomass and Energy Technologies.

Wang, D., Ning, K., Li, J., Hu, J., Han, D., Wang, H., Zeng, X., Jing, X., Zhou, Q., Su, X., Chang, X., Wang, A., Wang, W., Jia, J., Wei, L., Xin, Y., Qiao, Y., Huang, R., Chen, J., Han, B., Yoon, K., Hill, R.T., Zohar, Y., Chen, F., Hu, Q., Xu, J., 2014. Nannochloropsis genomes reveal evolution of microalgal oleaginous traits. PLoS Genet. 10, e1004094. 